\title{
Influenza Vaccination Rates Among Parents and Health Care Personnel in a German Neonatology Department
}

\author{
Horst Buxmann $^{1, *}$, Anne Daun ${ }^{1}$, Sabine Wicker ${ }^{2}$ (D) and Rolf Lambert Schlößer ${ }^{1}$ \\ 1 Department for Children and Adolescents, Division for Neonatology, University Hospital Frankfurt, \\ Goethe University, Theodor-Stern-Kai 7, D-60590 Frankfurt/Main, Germany; \\ anne.daun@kgu.de (A.D.); rolf.schloesser@kgu.de (R.L.S.) \\ 2 Occupational Health Service, University Hospital Frankfurt, Goethe University, Theodor-Stern-Kai 7, \\ D-60590 Frankfurt, Germany; sabine.wicker@kgu.de \\ * Correspondence: horst.buxmann@kgu.de; Tel.: +49-69-6301-5524; Fax: +49-69-6301-4757
}

Received: 13 November 2017; Accepted: 3 January 2018; Published: 5 January 2018

\begin{abstract}
The influenza vaccination is recommended for all German pregnant women and health care personnel (HCP). We are the first to publish vaccination rates of mothers of hospitalized newborns and HCP in neonatal units. Between September 2016 and March 2017, data were collected in our level-III neonatology department in this descriptive multidisciplinary study, using an anonymous questionnaire. As a result, 513 persons were asked to participate, including 330 parents and $183 \mathrm{HCP}$. We received an $80.3 \%(412 / 513)$ response rate, $87.3 \%(288 / 330)$, and $67.8 \%(124 / 183)$ from parents and HCP, respectively. Ten percent $(16 / 160)$ of mothers and $4.7 \%(6 / 127)$ of fathers had been vaccinated in 2016-2017 and 54.4\% (87/160) mothers and 52.2\% (66/127) fathers ever in their lifetime. In 2016-2017, $51.2 \%(21 / 41)$ of physicians had been vaccinated, $25.5 \%(14 / 55)$ of nurses, and $50.0 \%(14 / 28)$ of other staff members. When comparing those who had more than five influenza vaccinations in their life time, physicians were at $43.9 \%(18 / 41)$ versus nurses at $10.9 \%(6 / 55)(p<0.01)$, and other HCP at $7.4 \%(2 / 27)(p<0.01)$. The influenza vaccine uptake rate of $10 \%$ in mothers of hospitalized neonates is disappointingly low, resulting in $90 \%$ of hospitalized neonates being potentially vulnerable to influenza infection at a time where the risk for influenza-related complication can be severe.
\end{abstract}

Keywords: influenza vaccine; vaccination rates; pregnancy; neonate; preterm; neonatal intensive care unit; health care personnel

\section{Introduction}

Current German guidelines [1] recommend the influenza vaccination for all pregnant women without contraindications. This recommendation includes all health care personnel (HCP) and people who could be an origin of infection to persons-at-risk for a severe course of influenza disease. Preterm infants, particularly very low birth weight infants, are likely to develop severe influenza infections, and related complications, due to their immature immune systems, including deficits in B-cell function [2]. Therefore, both parents of preterm infants should be vaccinated against influenza during the season. The vaccine uptake rate in this area was not known. To address this gap in knowledge, we evaluated the vaccination rates among parents and the HCP of patients in our level-III neonatology department. 


\section{Materials and Methods}

\subsection{Study Design and Participants}

In this descriptive multidisciplinary study, an anonymous questionnaire about active vaccination against influenza was provided to parents of hospitalized neonates and HCP with contact to these patients, after written informed consent was obtained, at the level-III neonatology department of the University Hospital Frankfurt/Main, Germany between 1 September 2016 and 31 March 2017. To preserve anonymity, the recirculation of the innominate questionnaires occurred by using closed letter boxes in the wards.

\subsection{Questionnaire}

The questionnaire for the parents and HCP included the following nine questions: (1) If the person has been vaccinated against influenza in the 2016/2017season? (2) If the person has ever been vaccinated against influenza and how often? (3) Why the person would let themselves be vaccinated against influenza? (4) If the person thinks that the vaccination against influenza is effective? (5) Reasons why a person would not let themselves be vaccinated. (6) Would the person let themselves be vaccinated against influenza if they had a better knowledge about this vaccination? (7) The person's estimated likelihood of catching the flu in the next season if they are not vaccinated? (8) If the person thinks that influenza is an illness which can be severe? (9) About the persons attitude concerning vaccinations in general. Additionally, the parents were asked if they were the mother or the father of the neonate, and the HCP were asked about their gender and their profession within the health care system: physician, nurse, or other profession.

\subsection{Statistical Analysis}

Data collection and the descriptive analysis were conducted with Microsoft Excel 2010 (Microsoft Corp., Redmond, Washington, DC, USA). Differences in dichotomous variables were calculated with Fisher's exact test. $p$-values less than 0.05 were considered as statistically significant. Statistical analysis was performed with BIAS 11.6 by Hanns Ackermann, Biomathematics, Johann Wolfgang Goethe University, Frankfurt/Main, Germany.

\subsection{Ethics}

This study was approved by the Ethics Committee of the University Hospital Frankfurt, Goethe University, Germany (reference number: 177/16).

\section{Results}

During the study period, 513 persons were informed about, and asked to participate in the study, of which 330 were parents, representing $47.8 \%$ of 690 eligible parents and 183 were HCP representing $90.6 \%$ of 202 eligible HCP. We received back $80.3 \%(412 / 513)$ of the questionnaires: $87.3 \%$ (288/330) from all parents, 55.7\% (160/287), of which were female, $44.3 \%(127 / 287)$ were male; and one survey with no gender information. We received $67.8 \%$ of the surveys $(124 / 183)$ provided to all HCP, including 44.3\% (55/124) from nurses, 33.1\% (41/124) from physicians; and, 22.6\% (28/124) from other staff-members like physiotherapists, paramedics, and cleaning personnel, for example (Figure 1).

Not all of the participants answered all the questions, with a maximum of three lacking answers per questionnaire. The missing answers are specified in Table 1 . Ten percent $(16 / 160)$ of the mothers and $4.7 \%(6 / 127)$ of the fathers whose neonates were patients in our department had been vaccinated in the 2016-2017 season. In terms of having been vaccinated ever, at least once, 54.4\% (87/160) of the mothers and $52.2 \%(66 / 127)$ of the fathers responded with an affirmative to this question. 


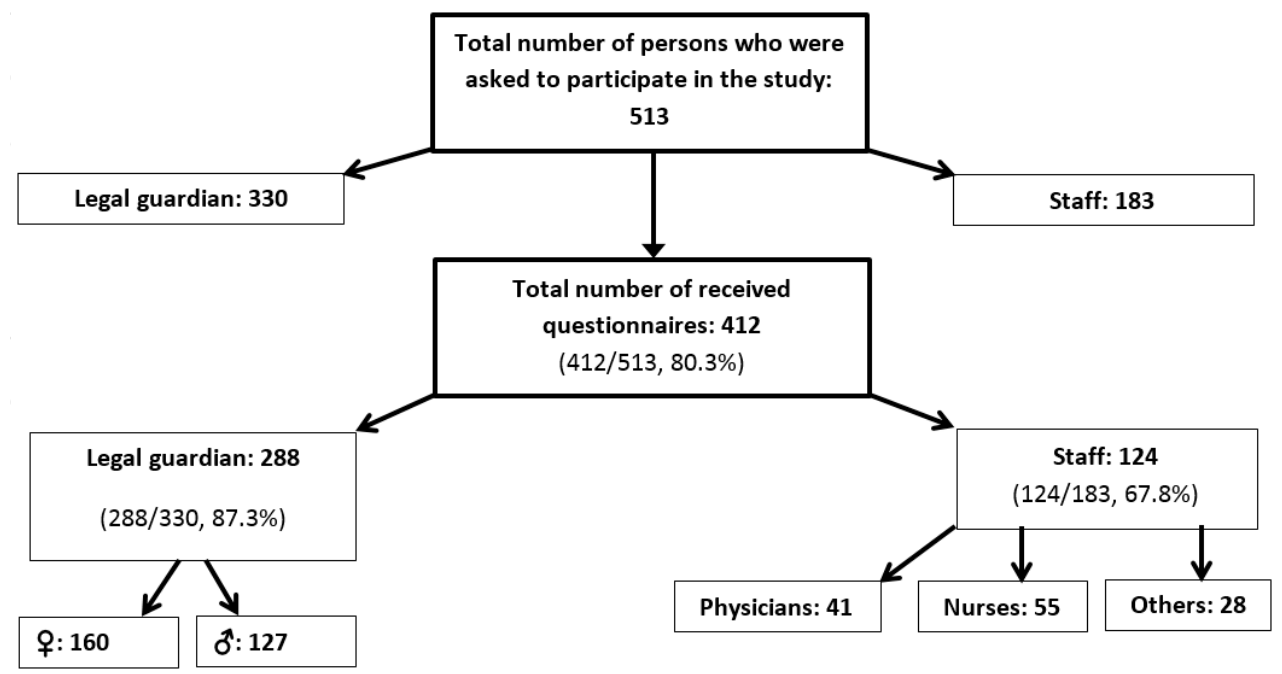

Figure 1. Flow chart of the recruitment process for the study.

These vaccination rates are significantly lower than the $39.9 \%(49 / 124 ; p<0.01)$ of vaccinated HCP in the 2016-2017 season and significantly lower than the lifetime HCP vaccination rate of $74.8 \%(92 / 123 ; p=0.03)$.

Focusing on the HCP, $90.2 \%$ (37/41) of physicians showed a tendency to be more often vaccinated in their lifetime, at least once, when compared to other staff-members with $77.8 \%(21 / 27)$, and nurses with $61.8 \%$ (34/55). Physicians were also more likely to be vaccinated in the 2016-2017 season, at $51.2 \%(21 / 41)$, when compared to other staff members at 50.0\% (14/28), and nurses at $25.5 \%(14 / 55)$. These differences were statistically not significant. In terms of receiving more than five influenza vaccinations in their lifetime, physicians, at $43.9 \%(18 / 41)$, were vaccinated significantly more often than nurses, at $10.9 \%(6 / 55 ; p<0.01)$, and other HCP at $7.4 \%(2 / 27 ; p<0.01)$.

The motivation for parents and HCP to allow for themselves to be vaccinated was predominantly to protect the neonates, followed by self-protection, and protection for other family members and friends (Table 1). A minority, more HCP than parents, believed in the effectiveness of active vaccination against influenza. Within the HCP group, significantly more physicians and other staff members believed that this vaccination is efficacious when compared to nurses (physicians vs. nurses; $p=0.02$ ). The most often named reason why a person would not allow themselves to be vaccinated, was "no expected specific risk" for parents with 37.5\% (95/253). Interestingly, four mothers stated that they did not allow themselves to be vaccinated against influenza, because they had been pregnant. For the HCP group, expected "missing efficacy" of the vaccination was the most named factor to not allow themselves to be vaccinated, in which nurses choose this argument significantly more often than physicians $(69.0 \%(29 / 42)$ vs. $22.2 \%(4 / 18) ; p=0.04)$.

If they had better knowledge about the influenza vaccination, more parents than HCP would allow themselves to be vaccinated. This difference was highly statistically significant when mothers were compared to nurses $(p<0.01)$. The estimated likelihood of catching the flu in the next season if not vaccinated was significantly higher in the HCP group when compared to the parents group $(p<0.01)$. Significantly more HCP agreed to the statement that "influenza is an illness that could take a severe course" compared to parents $(p=0.02)$. Within the HCP group, significantly more physicians agreed to this declaration when compared to nurses with $(p<0.01)$. Concerning vaccinations in general, HCP favor vaccinations compared to parents $(p<0.01)$. Within the HCP group, the support of vaccinations in general was significantly higher in physicians and other $\mathrm{HCP}$, as compared to nurses $(p<0.05)$. The questions and answers are shown in Table 1. 
Table 1. All questions and answers provided in response to the vaccination questionnaire.

\begin{tabular}{|c|c|c|c|c|c|c|c|}
\hline $\begin{array}{l}\text { Question No. 1: Have You been Vaccinated } \\
\text { Against Influenza in the Actual Season } \\
\text { (September } 2016 \text { to April 2017)? }\end{array}$ & Parents & Mothers & Fathers & $\begin{array}{l}\text { Health Care } \\
\text { Personnel }\end{array}$ & Physicians & Nurses & $\begin{array}{l}\text { Other Health } \\
\text { Care Personne }\end{array}$ \\
\hline Yes & $22 / 288(7.6 \%)$ & $16 / 160(10 \%)$ & $6 / 127(4.7 \%)$ & $49 / 124(39.5 \%)$ & $21 / 41(51.2 \%)$ & $14 / 55(25.5 \%)$ & $14 / 28(50.0 \%)$ \\
\hline No & $266 / 288(92.4 \%)$ & $144 / 160(90 \%)$ & $121 / 127(95.3 \%)$ & $75 / 124(60.5 \%)$ & $20 / 41(48.8 \%)$ & $41 / 55(74.5 \%)$ & $14 / 28(50.0 \%)$ \\
\hline No answer to this question & $0 / 288$ & $0 / 160$ & $0 / 127$ & $0 / 124$ & $0 / 41$ & $0 / 55$ & $0 / 28$ \\
\hline \multicolumn{8}{|l|}{$\begin{array}{l}\text { Question No. 2: Have You Ever been Vaccinated } \\
\text { Against Influenza? }\end{array}$} \\
\hline Never & $134 / 288(46.5 \%)$ & $73 / 160(45.6 \%)$ & $61 / 127(48.0 \%)$ & $31 / 123(25.2 \%)$ & $4 / 41(9.8 \%)$ & $21 / 55(38.2 \%)$ & $6 / 27(22.2 \%)$ \\
\hline Once & $83 / 288(28.8 \%)$ & $44 / 160(27.5 \%)$ & $38 / 127(29.9 \%)$ & $26 / 123(21.1 \%)$ & $6 / 41(14.6 \%)$ & $12 / 55(21.8 \%)$ & $8 / 27(29.6 \%)$ \\
\hline $2-5$ times & $55 / 288(19.1 \%)$ & $33 / 160(20.6 \%)$ & $22 / 127(17.3 \%)$ & $40 / 123(32.5 \%)$ & $13 / 41(31.7 \%)$ & $16 / 55(29.1 \%)$ & $11 / 27(40.7 \%)$ \\
\hline More than 5 times & $16 / 288(5.6 \%)$ & $10 / 160(6.3 \%)$ & $6 / 127(4.7 \%)$ & $26 / 123(21.1 \%)$ & $18 / 41(43.9 \%)$ & $6 / 55(10.9 \%)$ & $2 / 27(7.4 \%)$ \\
\hline No answer to this question & $0 / 288$ & $0 / 160$ & $0 / 127$ & $1 / 124(0.8 \%)$ & $0 / 41$ & $0 / 55$ & $1 / 28(3.6 \%)$ \\
\hline \multicolumn{8}{|l|}{$\begin{array}{l}\text { Question No. 3: Why Would You Let Yourself } \\
\text { Vaccinate Against Influenza? (More Than One } \\
\text { Answer Possible) }\end{array}$} \\
\hline Self-protection & $155 / 241(64.3 \%)$ & $87 / 132(65.9 \%)$ & $67 / 108(62.0 \%)$ & $82 / 124(66.1 \%)$ & $31 / 40(77.5 \%)$ & $29 / 38(76.3 \%)$ & $22 / 26(84.6 \%)$ \\
\hline Family and friends & $160 / 241(66.4 \%)$ & $84 / 132(63.6 \%)$ & $76 / 108(70.4 \%)$ & $68 / 124(54.8 \%)$ & $29 / 40(72.5 \%)$ & $24 / 38(63.2 \%)$ & $15 / 26(57.7 \%)$ \\
\hline Children/patients & $185 / 241(76.8 \%)$ & $102 / 132(77.3 \%)$ & $83 / 108(76.9 \%)$ & $92 / 124(74.2 \%)$ & $39 / 40(97.5 \%)$ & $32 / 38(84.2 \%)$ & $21 / 26(80.8 \%)$ \\
\hline No answer to this question & $47 / 288(16.3 \%)$ & $28 / 160(17.5 \%)$ & $19 / 127(15.0 \%)$ & $20 / 124(16.1 \%)$ & $1 / 41(2.4 \%)$ & $17 / 55(30.9 \%)$ & $2 / 28(7.1 \%)$ \\
\hline \multicolumn{8}{|l|}{$\begin{array}{l}\text { Question No. 4: Do You Think the Vaccination } \\
\text { Against Influenza is Effective? }\end{array}$} \\
\hline Yes & $74 / 285(26.0 \%)$ & $42 / 159(26.4 \%)$ & $31 / 125(24.8 \%)$ & $45 / 124(36.3 \%)$ & $19 / 41(46.3 \%)$ & $10 / 55(18.2 \%)$ & $15 / 28(53.6 \%)$ \\
\hline No & $19 / 285(6.7 \%)$ & $11 / 159(6.9 \%)$ & $8 / 125(6.4 \%)$ & $13 / 124(10.5 \%)$ & $0 / 41$ & $12 / 55(21.8 \%)$ & $1 / 28(3.6 \%)$ \\
\hline Partly & $126 / 285(44.2 \%)$ & $75 / 159(47.2 \%)$ & $51 / 125(40.8 \%)$ & $63 / 124(50.8 \%)$ & $21 / 41(51.2 \%)$ & $31 / 55(56.4 \%)$ & $11 / 28(39.3 \%)$ \\
\hline Don't know & $66 / 285(23.2 \%)$ & $31 / 159(19.5 \%)$ & $35 / 125(28.0 \%)$ & $4 / 124(3.2 \%)$ & $1 / 41(2.4 \%)$ & $2 / 55(3.6 \%)$ & $1 / 28(3.6 \%)$ \\
\hline No answer to this question & $3 / 288(1.0 \%)$ & $1 / 160(0.6 \%)$ & $2 / 127(1.6 \%)$ & $0 / 124$ & $0 / 41$ & $0 / 55$ & $0 / 28$ \\
\hline \multicolumn{8}{|l|}{$\begin{array}{l}\text { Question No. 5: Give Reasons, Why You } \\
\text { Would Not Let Yourself Get Vaccinated } \\
\text { Against Influenza? }\end{array}$} \\
\hline Planned to get vaccinated, but not done yet & $42 / 253(16.6 \%)$ & $23 / 136(16.9 \%)$ & $19 / 116(16.4 \%)$ & $14 / 73(19.2 \%)$ & $8 / 18(44.4 \%)$ & $5 / 42(11.9 \%)$ & $1 / 13(7.6 \%)$ \\
\hline No specific risk & $95 / 253(37.5 \%)$ & $49 / 136(36.0 \%)$ & $45 / 116(38.8 \%)$ & $19 / 73(26.0 \%)$ & $2 / 18(11.1 \%)$ & $14 / 42(33.3 \%)$ & $3 / 13(23.1 \%)$ \\
\hline No severe illness & $59 / 253(23.3 \%)$ & $34 / 136(25.0 \%)$ & $25 / 116(21.6 \%)$ & $8 / 73(11.0 \%)$ & $1 / 18(5.6 \%)$ & $5 / 42(11.9 \%)$ & $2 / 13(15.4 \%)$ \\
\hline No protective effect & $60 / 253(23.7 \%)$ & $32 / 136(23.5 \%)$ & $28 / 116(24.1 \%)$ & $38 / 73(52.1 \%)$ & $4 / 18(22.2 \%)$ & $29 / 42(69.0 \%)$ & $5 / 13(38.5 \%)$ \\
\hline Afraid of unexpected side effects & $78 / 253(30.8 \%)$ & $43 / 136(31.6 \%)$ & $35 / 116(30.2 \%)$ & $28 / 73(38.4 \%)$ & $6 / 18(33.3 \%)$ & $20 / 42(47.6 \%)$ & $3 / 13(23.1 \%)$ \\
\hline Afraid of injections & $8 / 253(3.2 \%)$ & $4 / 136(2.9 \%)$ & $4 / 116(3.4 \%)$ & $1 / 73(1.4 \%)$ & $1 / 18(5.6 \%)$ & $0 / 42$ & $0 / 13$ \\
\hline Causes influenza & $56 / 253(22.1 \%)$ & $30 / 136(22.1 \%)$ & $26 / 116(22.4 \%)$ & $19 / 73(26.0 \%)$ & $2 / 18(11.1 \%)$ & $14 / 42(33.3 \%)$ & $3 / 13(23.1 \%)$ \\
\hline No time & $31 / 253(12.3 \%)$ & $10 / 136(7.4 \%)$ & $21 / 116(18.1 \%)$ & $8 / 73(11.0 \%)$ & $7 / 18(38.9 \%)$ & $1 / 42(2.4 \%)$ & $1 / 13(7.7 \%)$ \\
\hline Forgotten & $26 / 253(10.3 \%)$ & $11 / 136(8.1 \%)$ & $15 / 116(12.9 \%)$ & $8 / 73(11.0 \%)$ & $2 / 18(11.1 \%)$ & $1 / 42(2.4 \%)$ & $4 / 13(30.8 \%)$ \\
\hline Doctor advised against it. & $36 / 253(14.2 \%)$ & $19 / 136(14.0 \%)$ & $17 / 116(14.7 \%)$ & $4 / 73(5.5 \%)$ & $0 / 18$ & $0 / 42$ & $4 / 13(30.8 \%)$ \\
\hline No answer to this question. & $35 / 288(12.2 \%)$ & $24 / 160(15.0 \%)$ & $11 / 127(8.7 \%)$ & $51 / 124(41.1 \%)$ & $23 / 41(56.1 \%)$ & $13 / 55(23.6 \%)$ & $15 / 28(53.6 \%)$ \\
\hline
\end{tabular}


Table 1. Cont

\begin{tabular}{|c|c|c|c|c|c|c|c|}
\hline \multicolumn{8}{|c|}{$\begin{array}{l}\text { Question No. 6: Would You Let Yourself Get } \\
\text { Vaccinated Against Influenza if You Had a Better } \\
\text { Knowledge About This Vaccination? }\end{array}$} \\
\hline Yes & $104 / 264(39.4 \%)$ & $61 / 146(41.8 \%)$ & $43 / 117(36.8 \%)$ & 20/83 (24.1\%) & 9/22 (40.9\%) & $2 / 41(4.9 \%)$ & $9 / 20(45.0 \%)$ \\
\hline No & $47 / 264(17.8 \%)$ & $31 / 146(21.2 \%)$ & $16 / 117(13.7 \%)$ & $34 / 83(41.0 \%)$ & $9 / 22(40.9 \%)$ & $21 / 41(51.2 \%)$ & $5 / 20(25.0 \%)$ \\
\hline Don't know & $112 / 264(42.4 \%)$ & $53 / 146(36.3 \%)$ & $58 / 117(49.6 \%)$ & $28 / 83(33.7 \%)$ & $4 / 22(18.2 \%)$ & $17 / 41(41.5 \%)$ & $6 \% 20(30.0 \%)$ \\
\hline No answer to this question. & $24 / 288(8.3 \%)$ & $14 / 160(8.8 \%)$ & $10 / 127(7.9 \%)$ & $41 / 124(33.1 \%)$ & $19 / 41(46.3 \%)$ & $14 / 55(24.5 \%)$ & $8 / 28(28.6 \%)$ \\
\hline \multicolumn{8}{|c|}{$\begin{array}{l}\text { Question No. 7: How Big is the Estimated } \\
\text { Likelihood to Catch the Flu in the Next Season If } \\
\text { You are Not Vaccinated? }\end{array}$} \\
\hline No risk & $32 / 280(11.4 \%)$ & $12 / 157(7.6 \%)$ & $19 / 122(15.6 \%)$ & $7 / 117(6.0 \%)$ & $0 / 38$ & 6/52 (11.5\%) & $1 / 27(3.7 \%)$ \\
\hline Almost no risk & $52 / 280(18.6 \%)$ & $30 / 157$ (19.1\%) & $22 / 122(18.0 \%)$ & $14 / 117$ (12.0\%) & $1 / 38(2.6 \%)$ & $8 / 52(15.4 \%)$ & $5 / 27(18.5 \%)$ \\
\hline Little risk & $87 / 280(31.1 \%)$ & $48 / 157(30.6 \%)$ & $39 / 122(32.0 \%)$ & $23 / 117(19.7 \%)$ & $9 / 38(23.7 \%)$ & $10 / 52(19.2 \%)$ & $4 / 27(14.8 \%)$ \\
\hline moderate & $79 / 280(28.2 \%)$ & $47 / 157(29.9 \%)$ & $32 / 122(26.2 \%)$ & $52 / 117(52.4 \%)$ & $17 / 38(44.7 \%)$ & $24 / 52(46.2 \%)$ & $11 / 27(40.7 \%)$ \\
\hline Quite big & $18 / 280(6.4 \%)$ & $13 / 157(14.6 \%)$ & $5 / 122(4.1 \%)$ & $13 / 117(11.1 \%)$ & $5 / 38(13.2 \%)$ & $3 / 52(5.8 \%)$ & $5 / 27(18.5 \%)$ \\
\hline Big & $8 / 280(2.9 \%)$ & $4 / 157(2.5 \%)$ & $4 / 122(3.3 \%)$ & $3 / 117(2.6 \%)$ & $2 / 38(5.3 \%)$ & $1 / 52(1.9 \%)$ & $0 / 27$ \\
\hline Very big & $4 / 280(1.4 \%)$ & $3 / 157(1.9 \%)$ & $1 / 122(0.8 \%)$ & $5 / 117(4.3 \%)$ & 4/38 (10.5\%) & $0 / 52$ & $1 / 27(3.7 \%)$ \\
\hline No answer to this question. & $8 / 288(2.8 \%)$ & $3 / 160(1.9 \%)$ & $5 / 127(3.9 \%)$ & $7 / 124(5.6 \%)$ & $3 / 41(7.3 \%)$ & $3 / 55(5.5 \%)$ & $1 / 28(3.6 \%)$ \\
\hline \multicolumn{8}{|c|}{$\begin{array}{l}\text { Question No. 8: Influenza is an Illness Which } \\
\text { could Take a Severe Course. }\end{array}$} \\
\hline Strongly disagree & $5 / 279(1.8 \%)$ & 3/157 (1.9\%) & 2/122 (1.6\%) & $0 / 121$ & $0 / 40$ & $0 / 52$ & $0 / 28$ \\
\hline Disagree & $9 / 279(3.2 \%)$ & $5 / 157(3.2 \%)$ & $4 / 122(3.3 \%)$ & $1 / 121(0.8 \%)$ & $0 / 40$ & $1 / 52(1.9 \%)$ & $0 / 28$ \\
\hline Disagree in most parts & 9/279 (3.2\%) & $5 / 157(3.2 \%)$ & 4/122 (3.3\%) & $3 / 121(2.5 \%)$ & $1 / 40(2.5 \%)$ & $1 / 52(1.9 \%)$ & $2 / 28(7.1 \%)$ \\
\hline Neutral & $80 / 279(28.7 \%)$ & $43 / 157(27.4 \%)$ & $37 / 122(30.3 \%)$ & $13 / 121(10.7 \%)$ & $2 / 40(5.0 \%)$ & $6 / 52(11.5 \%)$ & $4 / 28(14.3 \%)$ \\
\hline Agree in most parts & $60 / 279(21.5 \%)$ & $31 / 157(19.7 \%)$ & $29 / 122(23.8 \%)$ & $16 / 121(13.2 \%)$ & $3 / 40(7.5 \%)$ & 10/52 (19.2\%) & $3 / 28(10.7 \%)$ \\
\hline Agree & $79 / 279(28.3 \%)$ & $49 / 157(31.2 \%)$ & $30 / 122(24.6 \%)$ & $54 / 121(44.6 \%)$ & $13 / 40(32.5 \%)$ & $27 / 52(51.9 \%)$ & $13 / 28(46.4 \%)$ \\
\hline Strongly agree & $37 / 279(13.3 \%)$ & $21 / 157(13.4 \%)$ & $16 / 122(13.1 \%)$ & $34 / 121(28.1 \%)$ & $21 / 40(52.5 \%)$ & $7 / 52(13.5 \%)$ & $6 / 28(21.4 \%)$ \\
\hline No answer to this question. & $9 / 288(3.1 \%)$ & $3 / 160(1.9 \%)$ & $5 / 127(3.9 \%)$ & $3 / 124(2.4 \%)$ & $1 / 41(2.4 \%)$ & $2 / 55(2.6 \%)$ & $0 / 28$ \\
\hline \multicolumn{8}{|c|}{$\begin{array}{l}\text { Question No. 9: Which Attitude Concerning } \\
\text { Vaccinations in General Do You Agree Most with? }\end{array}$} \\
\hline Totally against & $2 / 278(0.7 \%)$ & $1 / 156(0.6 \%)$ & $1 / 127(0.8 \%)$ & $0 / 122$ & $0 / 40$ & $0 / 54$ & $0 / 28$ \\
\hline Mostly against & $3 / 278(1.1 \%)$ & $2 / 156(1.3 \%)$ & $1 / 127(0.8 \%)$ & $2 / 122(1.6 \%)$ & $0 / 40$ & $2 / 54(3.7 \%)$ & $0 / 28$ \\
\hline Partly against & $23 / 278(8.3 \%)$ & $16 / 156(10.3 \%)$ & $7 / 127(5.5 \%)$ & $6 / 122(4.9 \%)$ & $0 / 40$ & $5 / 54(9.3 \%)$ & $1 / 28(3.6 \%)$ \\
\hline Neutral & $81 / 278(29.1 \%)$ & $35 / 156(22.4 \%)$ & $46 / 127(36.2 \%)$ & 9/122 (7.4\%) & $0 / 40$ & $7 / 54(13.0 \%)$ & $2 / 28(7.1 \%)$ \\
\hline Partly for & $73 / 278(26.3 \%)$ & $46 / 156(29.5 \%)$ & $27 / 127(21.3 \%)$ & $22 / 122(18.0 \%)$ & $2 / 40(5.0 \%)$ & $14 / 54(25.9 \%)$ & $6 / 28(21.4 \%)$ \\
\hline Mostly for & $74 / 278(26.6 \%)$ & $40 / 156(25.6 \%)$ & $34 / 127(26.8 \%)$ & $40 / 122(32.8 \%)$ & $15 / 40(37.5 \%)$ & $18 / 54(33.3 \%)$ & $7 / 28(25.0 \%)$ \\
\hline Totally for & $22 / 278(7.9 \%)$ & $16 / 156(10.3 \%)$ & $6 / 127(4.7 \%)$ & $43 / 122(35.2 \%)$ & $23 / 40(57.5 \%)$ & $8 / 54(14.8 \%)$ & $12 / 28(42.9 \%)$ \\
\hline No answer to this question & $10 / 288(3.5 \%)$ & $4 / 160(2.5 \%)$ & $5 / 127(3.9 \%)$ & $2 / 124(1.6 \%)$ & $1 / 41(2.4 \%)$ & $1 / 55(1.8 \%)$ & $0 / 28$ \\
\hline
\end{tabular}




\section{Discussion}

\subsection{Parents}

To our knowledge, this is the first study on influenza vaccination rates among parents whose neonates are hospitalized in a level-III neonatology department. The vaccination rate found for 2016-2017 of $10.0 \%$ in mothers was very low and at $4.7 \%$ in fathers, was even lower. Given the current recommendation of the German Standing Committee on Vaccination [1] to vaccinate all pregnant women against influenza, these data are disappointing. Unfortunately, a comparable 7\% vaccination coverage in pregnant women was also found by Gaudelus et al. [3] in France, where the influenza vaccination is also recommended for all pregnant women. As a result, approximately $90 \%$ of the mothers from hospitalized term and preterm newborns in our cohort missed the chance to gain the well-described benefits of the influenza vaccination during pregnancy for their own health and that of their offspring [4]. The latter provides two benefits from the influenza vaccination of the mother: a reduced risk that the mother will be infected with influenza and transfers the virus to her baby, and the passive in utero immunization by materno-fetal influenza antibody transfer after vaccination during pregnancy $[5,6]$.

Why are the vaccination rates among pregnant women so low? It seems to be a combination of a lack of information, an underestimated risk of influenza infection, fear of adverse events, and doubt in the efficacy of the influenza vaccination. Nearly $40 \%$ of all the legal guardians answered that they would allow themselves to be vaccinated if they would have had a better knowledge about this vaccination. Four women in our cohort did not let themselves be vaccinated because they were pregnant, which is an indication for this vaccination, recommended by the German Standing Committee on Vaccination (STIKO) [1]. The most-provided statement by parents in question number five was that they do not perceive a risk of being infected with influenza. With respect to the vaccination itself, only a quarter of the parents believed in the efficacy and nearly one-third were afraid of unexpected side effects of this vaccination. Although many studies have shown that the influenza vaccination during pregnancy is safe $[4,7,8]$, the reported efficacy of about $50 \%$ in pregnant women [9] indicates considerable room for vaccine improvement.

\subsection{Health Care Personnel}

The vaccination rates among HCP (39.5\%) was significantly higher when compared to parents $(7.6 \%)$, both in the 2016-2017 season $(p<0.01)$, and at least once in their lifetime $(74.8 \%$ vs. 53.5\%, respectively; $p=0.03$ ). In comparison to other pediatric departments, these vaccination rates among the HCP are higher [10] or comparable [11]. Given the perceptions of parents of pediatric patients about influenza vaccinations in HCP, 76\% of the parents felt that all HCP should be vaccinated [12], to benefit the HCP themselves and their patients [13], along with the strong evidence-based recommendation for the influenza vaccination of HCP [1,14], these results could be improved upon.

The influenza vaccination rates within the HCP group were heterogeneous, showing the highest percentages for physicians both in the 2016-2017 season at 51.2\% and $90.2 \%$ ever. The lowest rates were reported for nurses with $25.5 \%$ in the 2016-2017 season and 61.8\% ever. This difference culminated in the highly significant difference concerning five or more influenza vaccinations ever, with $43.9 \%$ of all physicians and $10.9 \%$ of all nurses $(p<0.01)$, responding to this question in the affirmative. These findings align with those of Cozza et al. [10] and Pettke et al. [11] who also found higher vaccination rates among pediatric physicians when compared to pediatric nurses. This may be because significantly more physicians (46.3\%) trust in the efficacy of the influenza vaccination than nurses $(18.2 \%, p=0.02)$. Additionally, significantly more physicians stated that "influenza is an illness which could take a severe course" at $52.5 \%$ compared to $13.5 \%$ of nurses $(p<0.01)$ and physicians tend to be less afraid of unexpected side effects as compared to nurses, at $33.3 \%$ vs. $47.6 \%$, respectively (n.s.). Ofstead et al. [15] also found feared side effects (57.1\%), when considering the risk of influenza 
infection as low (44.4\%), and perceived poor vaccine effectiveness (31.3\%) as the main reasons for HCP to not get vaccinated against influenza.

The initiated vaccination promotion toolkit by Cozza et al. [10] unfortunately did not overcome their poor vaccination coverage of $14.2 \%$ in the five-year average in their pediatric department. Ofstead et al. [15] stated that "Strategies other than educational interventions are needed to increase influenza vaccination rates, and thereby to ensure healthcare worker and patient safety". Unfortunately, there are no strategies published in the current literature with reliable boosted influenza vaccination rates in $\mathrm{HCP}$ of pediatric departments.

\subsection{Limitations of the Study}

Some limitations exist in the interpretation of the results of this study. Since the survey was based on a convenience sample by a self-administered questionnaire, the findings may not be generalizable to the general population of parents and HCP in other settings. Moreover, only $67.8 \%$ of staff members and $87.3 \%$ of the parents returned the questionnaire. Unvaccinated persons may have been less motivated to complete this survey [16], and vaccination rates may be overestimated because of this non-response bias. Furthermore, we do not know whether respondents had influenza disease before and how the experience of the flu could affect their willingness to be vaccinated. In addition, some participants did not answer all questions, which also limited the accuracy of the data.

\section{Conclusions}

To our knowledge, this is the first study on influenza vaccination rates among parents and health care personnel in a neonatology department. The $10 \%$ influenza vaccine rate of former pregnant women whose neonates were hospitalized is disappointingly low. About $90 \%$ of pregnant women miss the unique opportunity to protect two individuals with one vaccination, by actively protecting themselves and passively protecting their hospitalized neonates. The vaccination rates in HCP of $39.5 \%$ in the $2016-2017$ season, and $74.8 \%$ in their lifetime, are comparable or even better than those found in other pediatric departments [10,11]. Physicians with $43.9 \%$ had significantly higher rates on more than five influenza vaccinations in their lifetime than nurses $(10.9 \%)$ and other HCP $(7.4 \%)$. There is much room for improvement.

Acknowledgments: Our sincere thanks go to all participating parents for their consent and support, making this study possible. We gratefully acknowledge all staff members of our multidisciplinary team, supporting this study.

Author Contributions: R.L.S., S.W. and H.B. planed and designed the study; H.B., A.D. and R.L.S. implemented the study and collected data; H.B., R.L.S., A.D. and S.W. analyzed data and wrote the paper. All authors read and approved the manuscript.

Conflicts of Interest: This research did not receive any specific grant from funding agencies in the public, commercial, or not-for-profit sectors. Sabine Wicker is a member of the German Standing Committee on Vaccination (STIKO). Until 2011 she has received honoraria for non-product-related talks on influenza vaccination from GlaxoSmithKline, Sanofi Pasteur, AstraZeneca and Novartis and has participated in work-shops about health care personnel and vaccination sponsored by Abbot. We, the authors of this article, certify that there is no other potential conflict of interest with any financial organization nor a non-financial interest in the subject matter discussed in this manuscript.

\section{References}

1. Statement of the German Standing Committee on Vaccination at the RKI; Recommendations of the Standing Committee on Vaccination (STIKO) at the Robert Koch Institute. In Epidemiologisches Bulletin; Robert Koch Institute: Berlin, Germany, 2017; Volume 34, pp. 333-380. [CrossRef]

2. Resch, B.; Kurath-Koller, S.; Eibisberger, M.; Zenz, W. Prematurity and the burden of influenza and respiratory syncytial virus disease. World J. Pediatr. 2016, 12, 8-18. [CrossRef] [PubMed]

3. Gaudelus, J.; Martinot, A.; Denis, F.; Stahl, J.P.; Chevaillier, O.; Lery, T.; Pujol, P.; Cohen, R. Vaccination of pregnant women in France. Med. Mal. Infect. 2016, 46, 424-428. [CrossRef] [PubMed] 
4. Sakala, I.G.; Honda-Okubo, Y.; Fung, J.; Petrovsky, N. Influenza immunization during pregnancy: Benefits for mother and infant. Hum. Vaccines Immunother. 2016, 12, 3065-3071. [CrossRef] [PubMed]

5. Regan, A.K.; Moore, H.C.; Sullivan, S.G.; De Klerk, N.; Effler, P.V. Epidemiology of seasonal influenza infection in pregnant women and its impact on birth outcomes. Epidemiol. Infect. 2017, 145, 2930-2939. [CrossRef] [PubMed]

6. Christian, L.M.; Beverly, C.; Mitchell, A.M.; Karlsson, E.; Porter, K.; Schultz-Cherry, S.; Ramilo, O. Effects of prior influenza virus vaccination on maternal antibody responses: Implications for achieving protection in the newborns. Vaccine 2017, 35, 5283-5290. [CrossRef] [PubMed]

7. Regan, A.K. The safety of maternal immunization. Hum. Vaccines Immunother. 2016, 12, 3132-3136. [CrossRef] [PubMed]

8. Loubet, P.; Kerneis, S.; Anselem, O.; Tsatsaris, V.; Goffinet, F.; Launay, O. Should expectant mothers be vaccinated against flu? A safety review. Expert Opin. Drug Saf. 2014, 13, 1709-1720. [CrossRef] [PubMed]

9. Thompson, M.G.; Li, D.K.; Shifflett, P.; Sokolow, L.Z.; Ferber, J.R.; Kurosky, S.; Bozeman, S.; Reynolds, S.B.; Odouli, R.; Henninger, M.L.; et al. Effectiveness of seasonal trivalent influenza vaccine for preventing influenza virus illness among pregnant women: A population-based case-control study during the 2010-2011 and 2011-2012 influenza seasons. Clin. Infect. Dis. 2014, 58, 449-457. [CrossRef] [PubMed]

10. Cozza, V.; Alfonsi, V.; Rota, M.C.; Paolini, V.; Ciofi degli Atti, M.L. Promotion of influenza vaccination among health care workers: Findings from a tertiary care children's hospital in Italy. BMC Public Health 2015, 15, 697. [CrossRef] [PubMed]

11. Pettke, A.; Jocham, S.; Wiener, A.; Löcken, A.; Groenefeld, J.; Ahlmann, M.; Groll, A.H. Vaccination against influenza at a European pediatric cancer center: Immunization rates and attitudes among staff, patients, and their families. Support. Care Cancer 2017. [CrossRef] [PubMed]

12. Linam, W.M.; Gilliam, C.H.; Honeycutt, M.; Wisdom, C.; Swearingen, C.J.; Romero, J.R. Parental perceptions about required influenza immunization of pediatric healthcare personnel. Infect. Control Hosp. Epidemiol. 2014, 35, 1301-1303. [CrossRef] [PubMed]

13. Ahmed, F.; Lindley, M.C.; Allred, N.; Weinbaum, C.M.; Grohskopf, L. Effect of influenza vaccination of healthcare personnel on morbidity and mortality among patients: Systematic review and grading of evidence. Clin. Infect. Dis. 2014, 58, 50-57. [CrossRef] [PubMed]

14. Griffin, M.R. Influenza vaccination of healthcare workers: Making the grade for action. Clin. Infect. Dis. 2014, 58, 58-60. [CrossRef] [PubMed]

15. Ofstead, C.L.; Tucker, S.J.; Beebe, T.J.; Poland, G.A. Influenza vaccination among registered nurses: Information receipt, knowledge, and decision-making at an institution with a multifaceted educational program. Infect. Control Hosp. Epidemiol. 2008, 29, 99-106. [CrossRef] [PubMed]

16. Llupia, A.; Garcia-Basteiro, A.L.; Mena, G.; Ríos, J.; Puig, J.; Bayas, J.M.; Trilla, A. Vaccination behaviour influences self-report of influenza vaccination status: A cross-sectional study among health care workers. PLoS ONE 2012, 7, e39496. [CrossRef] [PubMed]

(C) 2018 by the authors. Licensee MDPI, Basel, Switzerland. This article is an open access article distributed under the terms and conditions of the Creative Commons Attribution (CC BY) license (http:// creativecommons.org/licenses/by/4.0/). 